\title{
Psychometric properties for the Polish version of the Brief Illness Perception Questionnaire (Brief IPQ)
}

\section{BACKGROUND}

This study presents the Polish validation of the Brief IIIness Perception Questionnaire, a nine-item scale which was constructed to assess the cognitive and emotional representations of illness among Polish patients. This tool is derived from the Common-Sense Model of Self-Regulation of Health and Illness.

\section{PARTICIPANTS AND PROCEDURE}

This study included 923 chronically ill people with the following diseases: eczema (E), bronchial asthma (BA), chronic obstructive pulmonary disease (COPD), rheumatoid arthritis (RA), Hashimoto's disease (HD), diabetes type II (D), acne (A), glaucoma and cataract (G, C), HIV/ AIDS, ischaemic heart disease (IHD), psoriasis (P), breast and stomach cancer (C), and multiple sclerosis (MS). Testretest reliability was assessed in 358 patients with selected chronic illnesses. Concurrent validity was assessed by correlating Kurtzke's EDSS and the Brief IPQ in 140 MS patients. Discriminant validity was verified by comparing means for the tool among four groups of patients.

\section{RESULTS}

The Polish version of the Brief IPQ showed good test-retest reliability. The scale also demonstrates good concurrent validity in MS patients. The discriminant validity of the Brief IPQ was supported by its ability to distinguish among different illnesses.

\section{CONCLUSIONS}

The Brief IPQ is a good, short and easy to use tool for assessing the perceptions of illness among Polish patients.

\section{KEY WORDS}

illness perceptions; chronic illness; scale validation; Brief IPQ

Organization - 1: SWPS University of Social Sciences and Humanities, Sopot, Poland · 2: Department of General,

Endocrine and Transplant Surgery, Medical University of Gdansk, Gdansk, Poland

AUthors' COntributions - A: Study design - B: Data collection · C: Statistical analysis · D: Data interpretation ·

E: Manuscript preparation F: Literature search G: Funds collection

CORRESPONDING AUthor - Marlena M. Kossakowska, Ph.D., SWPS University of Social Sciences and Humanities,

16-20 Polna Str., 81-745 Sopot, Poland, e-mail: mkossakowska@swps.edu.pl, marlenakossakowska@gmail.com

to Cite this ARticle - Kossakowska, M. M., \& Stefaniak, T. J. (2017). Psychometric properties for the Polish version

of the Brief Illness Perception Questionnaire (Brief IPQ). Health Psychology Report, 5(1), 67-83.

doi: 10.5114/hpr.2017.61668

RECEIVED 16.02.2016 · REVIEWED 04.03.2016 · ACCEPTED 19.05.2016 · PUBLISHED 16.08.2016 


\section{BACKGROUND}

The theoretical background for this article is the self-regulation model developed by Leventhal and colleagues (Leventhal, Nerenz, \& Steele, 1984; Hagger \& Orbell, 2003). According to Leventhal's studies, ill people use their cognitive and emotional schemata to regulate their behaviours in appropriate directions, adequately to the adverse situation. The cognitive and emotional model of illness allows the ill person's situ-

Marlena M. Kossakowska, Tomasz J. Stefaniak ation to be interpreted and behaviour to be regulated accordingly. An ill person checks the individually assessed effectiveness of his/her behaviour in terms of its cognitive and behavioural results and either maintains the behaviour or adopts it to be useful and to bring satisfaction in everyday coping with the chronic condition. This self-regulatory model of Leventhal, Brissette, and Leventhal (2003), called the Common-Sense Model of Self-Regulation of Health and Illness, gives the subjective perception of illness a very significant role in coping with a chronic illness. First of all, illness perception influences the adherence to a range of medical recommendations. It is also a good indicator of how well a patient can cope with a chronic illness and of the emotional condition of a chronically ill person. Illness perceptions also regulate the functional adaptation to disabilities and severe conditions. The literature which deals with the role of illness perceptions in adaptation and coping with chronic illness is detailed in Table 1. The sources presented in the table show that individuals construct their internal representations or schema of their illness in order to interpret experiences obtained from the body and regulate their behaviour for particular purposes (Petrie \& Weinman, 2006). Patients build mental models of their illness to reduce the symptoms and psychological suffering at the emotional level. They also have a need to understand the functional role of the illness's impact on their lives, and finally they tend to make sense of it. Illness perceptions are defined as the emotional and cognitive representation of a physical condition in subjective terms. This representation contains beliefs about the aetiology of the illness, its symptoms, the subjective personal consequences of the illness, the extent to which the illness is amenable to control or cure and the personal perception of timeline (Weinman, Petrie, Moss-Morris, \& Horne, 1996).

All the studies cited in Table 1 were possible to perform due to the Illness Perception Questionnaire, which was constructed to assess illness perceptions among ill people (Weinman et al., 1996).

In Poland the precursors of research on cognitive and emotional representations of illness were Kulczycki (1971) and Heszen-Klemens (1979).

Illness Perception Questionnaire (IPQ). Weinman et al. (1996) created the Illness Perception Questionnaire, which previously contained 50 items. In 2002
Moss-Morris with her colleagues revised the IPQ into a 38-item tool. Finally, in 2006 the Brief Illness Perception Questionnaire (Brief IPQ; Broadbent, Petrie, Main, \& Weinman, 2006) was constructed as a short version of these two questionnaires. The items for the Brief IPQ were developed by forming one question that exemplified best the most important aspects of illness perceptions operationalized in the IPQ-R (Broadbent et al., 2006). Finally, only 9 major items were included for the brief version of the tool. All of the items, except the causal question, are rated using a 0 to 10 response scale.

Three versions of the IPQ (IPQ, IPQ-R, Brief IPQ) are very popular among health psychology researchers. These are multifactorial pencil-and-paper questionnaires, which assess cognitive and emotional illness representations on an eleven-point Likert scale (ibidem). Weinman et al. (1996) distinguish 5 domains of illness representations in the IPQ: identity, timeline, consequences, control/cure and causes. The IPQ-R version contains 7 domains of cognitive and emotional domains: timeline acute/chronic, timeline cyclical, consequences, personal control, treatment control, illness coherence, emotional representations (Moss-Morris et al., 2002). The causes are categorized as follows: 1) psychological attributions (stress or worry, mental attitude, problems in family, overwork, emotional state, personality), 2) risk factors (hereditary, diet or eating habits, poor medical care in the past, own behaviour, ageing, cigarettes, alcohol), 3) immunity (germs, viruses, pollution, altered immunity), 4) accident or chance (chance or bad luck, injury, accident).

The original Brief IPQ showed good test-retest reliability and concurrent validity (Broadbent et al., 2006). A systematic review and meta-analysis of 188 papers using the Brief IPQ, which was administered to patients aged from 8 to over 80 with a wide range of illnesses in 26 languages from 36 countries, revealed good psychometric properties. It also showed predictive power for specific outcomes at up to oneyear follow-up. The relationships between illness perceptions and depression, anxiety, blood glucose levels and quality of life were also confirmed (Broadbent et al., 2015).

\section{AIM OF THE STUDY}

The predictive power of illness perceptions and the wide use of them as a psychological construct among health researchers created the need for adapting the Polish version of the Brief Illness Perception Questionnaire. We noticed a growing interest among Polish researchers in using this questionnaire. Thus, the aim of this study is to present the psychometric properties of the Polish Brief Illness Perception Questionnaire and to verify whether this tool could be useful in a Polish population of ill people. 
Table 1

The role of illness perceptions in psychological functioning among chronically ill people. Literature review

\begin{tabular}{|c|c|}
\hline $\begin{array}{l}\text { Illness perceptions } \\
\text { as the predictor of... }\end{array}$ & Source \\
\hline \multirow{19}{*}{$\begin{array}{l}\text { 1) patients' adherence } \\
\text { to a range of medical } \\
\text { recommendations }\end{array}$} & Platt, Green, Jayasinghe, and Morrissey, 2014 \\
\hline & Massey et al., 2013 \\
\hline & Broadbent, Donkin, and Stroh, 2011 \\
\hline & Chen, Tsai, and Chou, 2011 \\
\hline & Nicklas, Dunbar, and Wild, 2010 \\
\hline & Chilcot, Wellsted, and Farrington, 2010 \\
\hline & Rees, Leong, Crowston, and Lamoureux, 2010 \\
\hline & Heijmans, 1999 \\
\hline & Kim and Evangelista, 2010 \\
\hline & Bucks et al., 2009 \\
\hline & Kaptein et al., 2008 \\
\hline & Gauchet, Tarquinio, and Fischer, 2007 \\
\hline & Llewellyn et al., 2003 \\
\hline & Llewellyn, Miners, Lee, Harrington, and Weinman, 2000 \\
\hline & Searle and Murphy, 2000 \\
\hline & Byer and Myers, 2000 \\
\hline & Griva, Myers, and Newman, 2000 \\
\hline & Horne et al., 2013 \\
\hline & Horne and Weinman, 1999 \\
\hline \multirow{10}{*}{$\begin{array}{l}\text { 2) the process of coping } \\
\text { with a chronic illness }\end{array}$} & Tiggelman, Ven, Schayck, Kleinjan, and Engels, 2014 \\
\hline & Mc Sharry, Moss-Morris, and Kendrick, 2011 \\
\hline & Rozema, Völlink, and Lechner, 2009 \\
\hline & Cartwright, Endean, and Porter, 2009 \\
\hline & Cheng, Chan, Hui, and Lam, 2003 \\
\hline & Helder et al., 2002 \\
\hline & Scharloo et al., 1998 \\
\hline & Scharloo et al., 2000 \\
\hline & Heijmans, 1998 \\
\hline & Heijmans and de Ridder, 1998 \\
\hline \multirow{3}{*}{$\begin{array}{l}\text { 3) the emotional state } \\
\text { observed in chronically } \\
\text { ill people }\end{array}$} & Edwards, Suresh, Lynch, Clarkson, and Stanley, 2001 \\
\hline & Fortune, Richards, Main, and Griffiths, 2000 \\
\hline & Murphy, Dickens, Creed, and Bernstein, 1999 \\
\hline \multirow{7}{*}{$\begin{array}{l}\text { 4) patients' functional } \\
\text { adaptation to disabil- } \\
\text { ities }\end{array}$} & Evans and Norman, 2009 \\
\hline & Moss-Morris and Chalder, 2003 \\
\hline & Whitmarsh, Koutantji, and Sidell, 2003 \\
\hline & Heijmans, 1998, 1999 \\
\hline & Moss-Morris, 1997 \\
\hline & Petrie and Weinman, 1996 \\
\hline & Scharloo et al., 1998 \\
\hline
\end{tabular}




\section{PARTICIPANTS AND PROCEDURE}

The data were being over the past 6 years (2008-2014). All individuals agreed to participate in this research and were informed about its major aim and their rights to refuse to participate without any consequences. All examinations were carried out in accordance with the privacy policy and ethical standards established by the Polish Psychological Association in the Psychologist's Code of Professional Ethics (Ko-

Marlena M. Kossakowska, Tomasz J. Stefaniak deks Etyczno-Zawodowy Psychologa, 1996). The consent for this research was issued by the Ethics Commission of the SWPS University of Social Sciences and Humanities (Warsaw, Poland) in accordance with the recommendations of the American Psychological Association and the Declaration of Helsinki.

Thirteen different groups of chronically ill patients participated in this study $(n=923)$. They suffered from Hashimoto's disease (HD), rheumatoid arthritis (RA), multiple sclerosis (MS), diabetes type II (D), ischaemic heart disease (IHD), breast and stomach cancer (C), bronchial asthma (BA), chronic obstructive pulmonary disease (COPD), psoriasis $(\mathrm{P})$, acne $(\mathrm{A})$, eczema (E), glaucoma and cataract (G, C), and HIV/AIDS. All participants were Polish. They were recruited from hospitals (41\%), associations (11\%) and some of them were out-patients $(23 \%)$. Twenty-five percent of patients filled in the questionnaire via the Internet, us-

ing a specially created Google Docs document. They were recruited via forums and social media.

The study was conducted individually. Each patient filled in the questionnaire in the presence of a psychologist or psychologist assistant or individually following detailed instructions (for example for people who completed the questionnaire via the Internet). Each patient had the possibility to ask the researcher questions (direct or via the researcher's e-mail address). Patients who participated in the test-retest study were asked to fill in the questionnaire again 6 weeks after the first measurement. Hospital patients were recruited from two institutions: the Medical College of Nicolaus Copernicus Medical University in Bydgoszcz and the Medical University of Gdansk (Poland). The remaining patients were members of associations for chronic people (e.g. the Polish Multiple Sclerosis Association). Demographic and clinical data for samples are presented in Table 2.

\section{MEASURES}

Brief IPQ. Illness perceptions were measured using the Brief Illness Perception Questionnaire, which consists of 8 items plus one open question about personal beliefs as to the causes of the illness. The first item: How much does your illness affect your life? (Jak bardzo choroba, na która chorujesz, wptywa na Twoje ży-

Table 2

Description of patients with chronic illnesses

\begin{tabular}{|c|c|c|c|c|c|c|c|c|}
\hline & \multirow[t]{2}{*}{$N$} & \multicolumn{2}{|c|}{ Gender } & \multicolumn{2}{|c|}{ Age (years) } & \multicolumn{2}{|c|}{$\begin{array}{l}\text { Illness duration } \\
\text { (in years) }\end{array}$} & \multirow[t]{2}{*}{ Range of age } \\
\hline & & females & males & $M$ & $S D$ & $M$ & $S D$ & \\
\hline Hashimoto's disease (HD) & 40 & 40 & 0 & 30.98 & 10.61 & 3.02 & 2.80 & $(0.10-16.00)$ \\
\hline $\begin{array}{l}\text { Ischaemic heart disease } \\
\text { (IHD) }\end{array}$ & 90 & 45 & 45 & 62.94 & 11.94 & 7.70 & 5.55 & $(0.10-51.00)$ \\
\hline Multiple sclerosis (MS) & 228 & 151 & 77 & 46.00 & 12.32 & 13.44 & 12.10 & $(1.00-57.00)$ \\
\hline Glaucoma, cataract $(\mathrm{G}, \mathrm{C})$ & 57 & 36 & 21 & 51.46 & 18.29 & 15.09 & 14.55 & $(0.10-67.00)$ \\
\hline Cancer (C) & 134 & 95 & 39 & 52.07 & 13.71 & 4.80 & 4.21 & $(0.10-22.00)$ \\
\hline Diabetes type II (D) & 42 & 20 & 22 & 56.24 & 14.00 & 9.70 & 8.96 & $(0.10-39.00)$ \\
\hline Psoriasis (P) & 95 & 59 & 36 & 36.22 & 13.76 & 15.04 & 10.58 & $(1.00-51.00)$ \\
\hline Eczema $(\mathrm{E})$ & 30 & 20 & 10 & 34.83 & 12.84 & 10.08 & 3.98 & $(1.00-12.00)$ \\
\hline Acne (A) & 52 & 32 & 20 & 18.98 & 6.08 & 7.01 & 2.87 & $(0.10-14.00)$ \\
\hline Rheumatoid arthritis (RA) & 35 & 30 & 5 & 51.77 & 19.47 & 14.18 & 13.88 & $(0.10-68.00)$ \\
\hline Bronchial asthma (BA) & 30 & 15 & 15 & 47.67 & 12.19 & 15.10 & 11.25 & $(0.10-40.00)$ \\
\hline $\begin{array}{l}\text { Chronic obstructive pul- } \\
\text { monary disease (COPD) }\end{array}$ & 30 & 12 & 18 & 62.70 & 12.94 & 8.34 & 6.28 & $(0.10-28.00)$ \\
\hline HIV/AIDS & 60 & 18 & 42 & 43.02 & 8.44 & 5.90 & 4.21 & $(2.00-34.00)$ \\
\hline Sum & 923 & 573 & 350 & 46.45 & 16.80 & 10.57 & 11.26 & $(0.10-68.00)$ \\
\hline
\end{tabular}


cie?) measures the Consequences of the illness (IP1). Item IP2, named Timeline, is the question: How long do you think your illness will continue? (Jak myślisz, jak dtugo Twoja choroba będzie trwać?) and indicates the subjective perception on a timeline. Item number 3: How much control do you feel you have over your illness? (Na ile jesteśs w stanie kontrolować swoja chorobę?) measures the Personal control over the illness (IP3). The next question: How much do you think your treatment can help your illness? (Jak myślisz, na ile leczenie może pomóc $w$ przezwyciężeniu Twojej choroby?) deals with beliefs about Treatment control (IP4). The fifth item: How much do you experience symptoms from your illness? (Wjakim stopniu doświadczasz objawów swojej choroby?) defines the illness identity understood in terms of symptoms' severity (IP5). It was named Identity. The item How concerned are you about your illness? (fak bardzo zamartwiasz się swojq choroba??) is a subjective perception of Concern about the illness (IP6). How well do you feel you understand your illness? (fak sadzisz, na ile rozumiesz swoja chorobę?) was formulated to measure comprehensibility (Understanding; IP7), sometimes called coherence (see Broadbent et al., 2006). Finally, the Emotional response (IP8) is represented by the question: How much does your illness affect you emotionally (e.g. does it make you angry, scared, upset or depressed)? (Na ile Twoja choroba wptywa na Twój stan emocjonalny, np. denerwuje Cię, złości, przeraża lub wprowadza Cie $w$ depresję?) (IP8). The bold letters indicate the names of the illness perception components. The ninth item of the Brief IPQ is a causal question. Patients are asked about three ideas regarding the causes of their particular illness. It is an open question where patients can come up with their own answers.

Translation process. During the adaptation process for the Polish version of the Illness Perception Questionnaire, the Polish translation was prepared with the application of the translation-back translation methodology. The questionnaire was translated into Polish by 4 bilinguals who were also professional translators. Two of them suffered from chronic illnesses (psoriasis and MS), while the other two were psychologists. Next, the questionnaire was translated back into English and the accuracy of translation was checked with two native speakers. They assessed the meaning of a particular item and what it was expected to measure. The author of this study decided with native speakers if the translation was proper and to what extent. Afterwards the Polish version was completed and, consequently, it was used in the validation process. The Polish Brief IPQ (ready to use) can be found on the website devoted to the Illness Perception Questionnaire: http://www. uib.no/ipq/. It was published there in 2004 .

Patient's Inventory was used to collect the demographic and clinical data. Patients were asked about their age, gender, educational level, marital status, profession and occupation. They were also asked about the following clinical features of chronic illness: illness duration, age at onset, symptoms, dynamic of illness (relapsing-remitting course, progressive etc., number of hospitalizations).

To assess the objective picture of the illness, Kurtzke's Expanded Disability Status Scale was used among patients suffering from multiple sclerosis (EDSS, Kurtzke, 1983). It assesses the disability status of people with multiple sclerosis on a scale from 0 to 10.00. For example: zero stands for a patient with normal neurological functioning, 5.0 stands for a patient able to walk unassisted for about 200 meters but whose disability impairs his/her daily activities, 9.5 stands for a patient unable to communicate effectively or eat/swallow. Neurologists were asked to assess the severity of patients' conditions.

Coping Orientations to Problems Experienced (COPE; Carver, Scheier, \& Weintraub, 1989) in its Polish adaptation (Wrześniewski, 1996) was used for concurrent validity assessment. This questionnaire identifies 8 strategies of coping with stress. In the modified version, the individual was asked about his/her coping with the stress caused by the chronic illness he/she currently experiences. The Polish version of COPE presents 8 different behaviours (in terms of strategies) applied in the face of a chronic disability. For assessing the aim of the following study we choose only three subscales. The first one measures the strategy named Problem Focused Coping (abbreviation: PROBLEM). It involves planning and carrying out actions through solving problems. The second one is Focus on and Venting of Emotions strategy (EMOTIONS), which concentrates on emotional expression and dealing with negative emotions such as anger and anxiety. The last strategy, named Acceptance (ACCEPTANCE), contains affirmative and confirmative behaviour applied in the face of illness. The Cronbach $\alpha$ coefficient in this study for the Polish version of COPE was .80 .

\section{RESULTS}

Data were analysed with the IBM SPSS Statistics v2.13 program. Basic statistics were represented by means, standard deviation, skewness and kurtosis. Pearson's coefficients were used to evaluate the relationships between measures. In order to assess the discriminant validity of the Brief IPQ one-way ANOVA was conducted with Tukey post hoc tests.

\section{BASIC STATISTICS}

Table 3 presents the results for means, standard deviations and ranges for all samples used in this research. These data can be carefully regarded as nor- 


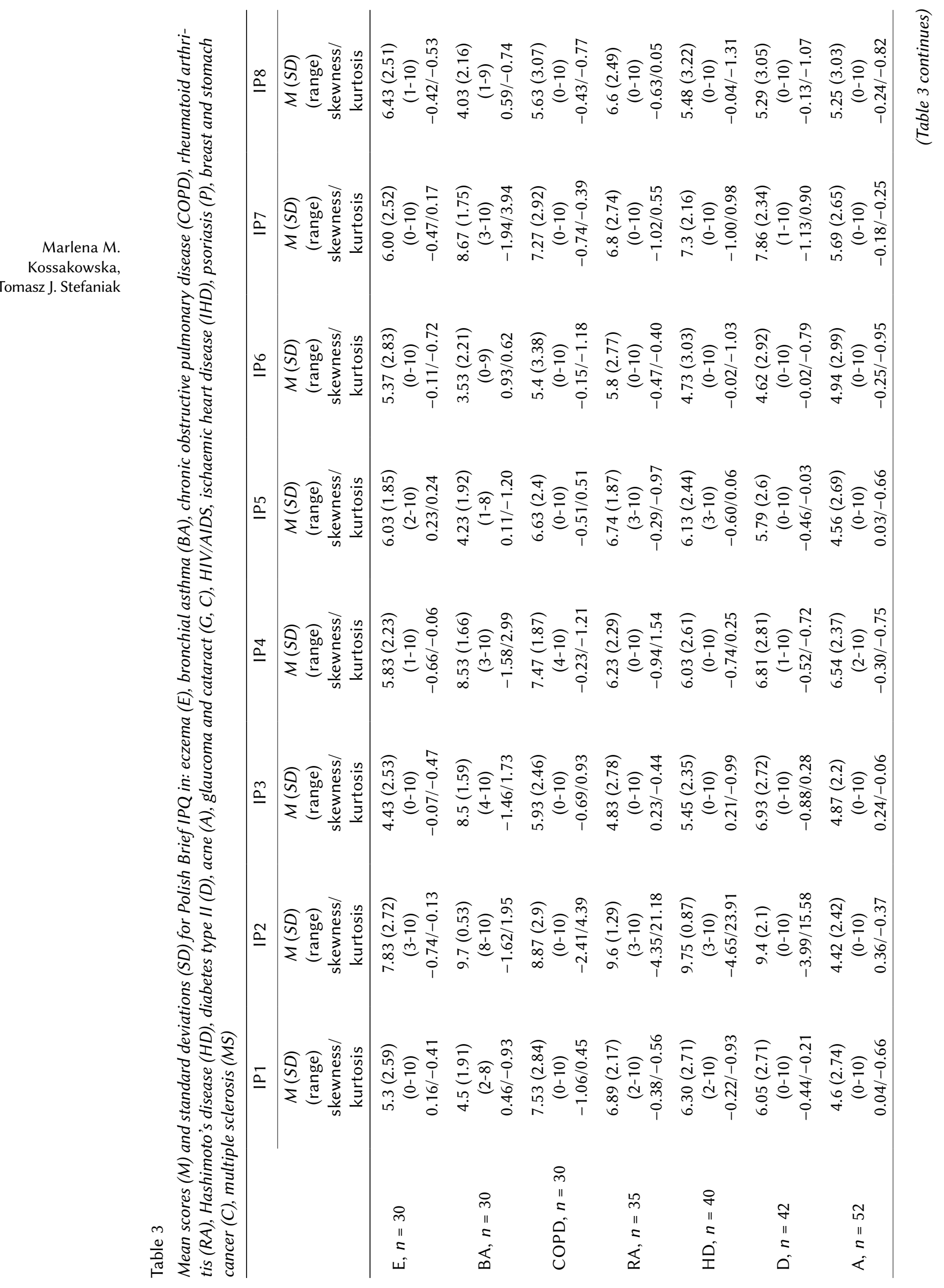




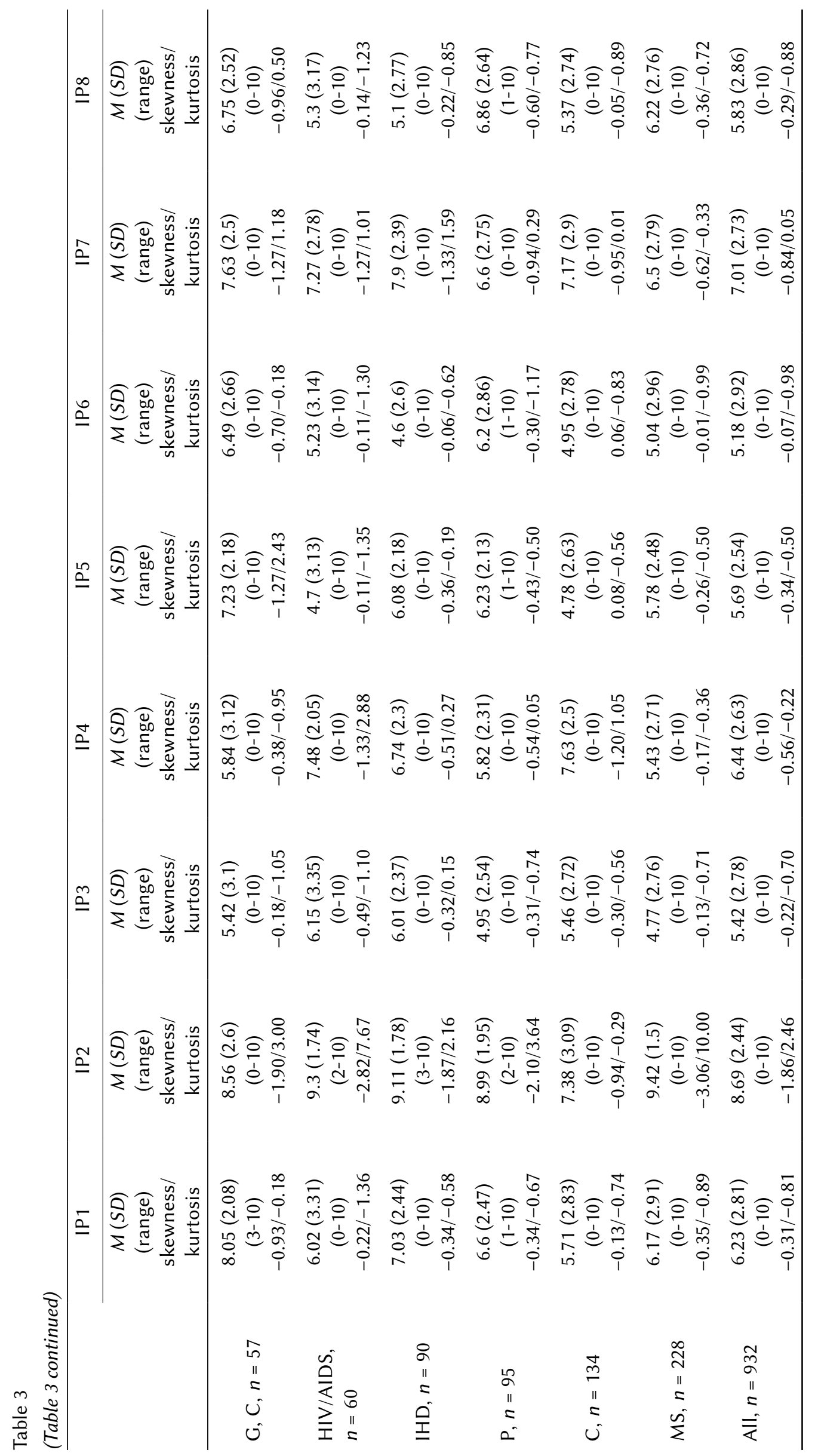

Polish Brief IPQ 
mative data for a particular chronic illness group, but sometimes the numbers for particular patient groups are too small to use them as normative. Due to that, interpretations of the results are limited. More stable results can be found in those groups where the number of participants exceeded 60: ischaemic heart disease, psoriasis, breast and stomach cancer and multiple sclerosis (Table 3).

Table 3 also presents the values for skewness and kurtosis. The following analysis gave more information

Marlena M. Kossakowska, Tomasz J. Stefaniak

about the variety of illness perceptions in patients. The skewness results are not very diverse. In the event of Timeline, the skewness is more diverse and shows negative values greater than one in 10 of 13 illnesses. This proves the majority of high results, which might seem strange since the illnesses are usually chronic so their duration is very long, close to "until the end of life". The distribution of results close to normal was noted in the cases of eczema, acne and cancers (Table 3). A similar situation appears with the Understanding item, but the deviation from normal distribution is definitely lower and occurs in 7 of 13 illnesses.

The kurtosis of results shows the leptokurtic distribution for the Timeline item in 8 of 13 illnesses. The distribution of results is slimmer in comparison with the normal distribution, which means the distribution is more clustered around the mean. In some instances the kurtosis results are highly in excess of 0 , but for the remaining items these are only isolated cases (Table 3). To sum up the skewness and kurtosis data, the symmetry of distributions (with only a few exceptions) is generally present (except for Timeline), and the distribution of results is close to normal (except for Timeline).

\section{RELIABILITY}

\section{Internal reliability}

Pearson's correlation coefficients were computed to investigate the inter-relationships between the Brief

Table 4

Correlations between items in the Polish Brief IPQ

\begin{tabular}{|c|c|c|c|c|c|c|c|}
\hline & IP1 & IP2 & IP3 & IP4 & IP5 & IP6 & IP7 \\
\hline \multicolumn{8}{|l|}{ IP1 Consequences } \\
\hline IP2 Timeline & $.24^{*}$ & & & & & & \\
\hline IP3 Personal control & $-.17^{*}$ & .04 & & & & & \\
\hline IP4 Treatment control & $-.15^{*}$ & $-.20^{*}$ & $.39^{*}$ & & & & \\
\hline IP5 Identity & $.57^{*}$ & $.19^{*}$ & $-.19^{*}$ & $-.18^{*}$ & & & \\
\hline IP6 Concern & $.53^{*}$ & .04 & $-.17^{*}$ & -.07 & $.44^{*}$ & & \\
\hline IP7 Understanding & .00 & $.13^{*}$ & $.29^{*}$ & $.17^{*}$ & .01 & -.09 & \\
\hline IP8 Emotional response & $.51^{*}$ & $.12^{*}$ & $-.17^{*}$ & $-.13^{*}$ & $.45^{*}$ & $.69^{*}$ & -.05 \\
\hline
\end{tabular}

IPQ items. The results are shown in Table 4. Generally speaking, the majority of items correlate with one another. Some of them correlate positively and some negatively, which depends on the positive/negative formulation of the question. For describing Pearson's $r$ coefficients, the negative/positive sign does not need to be distinguished. The most important issue is to assess whether there exist relations between items.

As we can see in Table 4, the highest correlations between items were achieved with regard to Consequences and Identity, Concern and Emotional Response. The more severe symptoms are reported by a patient or the more the patient worries about the illness and experiences a lot of unpleasant emotions (e.g. sorrow, anger), the more willingly the patient declares that the illness greatly affects his/her life. These difficult emotions experienced by the patient during illness are highly correlated with the severity of the illness and worrying about it. Similarly, Concern correlates with Identity. These components of the illness perceptions are related to one another, and the correlation ratios are between .44 and .69. Both probably share a common variance, although such a hypothesis would need to be verified in separate research. It is worth noting that one item, the Understanding item, does not correlate at all with these three aspects of illness (IP1, IP5, IP6). This item correlates highly with Personal Control, and less but still significantly with Treatment Control and Timeline. However, it is worth noting that none of the items correlates with all the remaining items, which is quite interesting and puzzling for a researcher.

The test-retest reliability was measured by having 8 groups of chronically ill patients complete the Polish Brief IPQ twice. The second measure was carried out 6 weeks after the first. The respondents were 358 individuals suffering from the diseases HD, IHD, MS, BC, D, P, RA, and BA (Table 5). The sizes of the groups were different (from $n=11$ - psoriasis to $n=60$ - ischaemic heart disease). The Polish Brief IPQ

Note. ${ }^{*} p<.05$ 
presents good consistency over the 6-week period. When considering details of particular illnesses we can note that consistency depends on illness perceptions and the size of the sample. In the group of as many as 358 persons (the total number of all patients regardless of the illness type) the measurement of the illness perceptions in both time periods is correlated in all items. There are only single cases in the group of Hashimoto disease, multiple sclerosis and breast cancer patients. There are no correlations in IP7 among patients with multiple sclerosis and breast cancer. There is also no relationship between IP3 in Hashimoto disease patients. In the remaining groups of patients (ischaemic heart disease, diabetes II type, psoriasis, rheumatoid arthritis and bronchial asthma) Pearson correlations demonstrate that items have good test-retest reliability over both time periods (Table 5).

\section{EXTERNAL VALIDITY}

To assess the concurrent validity of the Brief IPQ, we checked the correlation between illness perceptions and other factors. We assumed that illness perceptions should be independent of gender and other demographic characteristics (age and educational level) and they should be dependent on clinical variables (e.g. illness duration, age at the onset and other objective measures of patients' conditions). To check this hypothesis, Pearson's $r$ coefficients were determined between the Brief IPQ items and demographic and clinical data (Table 6). There are no relations between the Brief IPQ and gender and educational level (besides one weak correlation with Timeline) among
Polish patients, whereas age is associated with 5 of 8 Brief IPQ aspects (Table 6). The older the patient is, the more he or she feels the impact of the illness on life $(r=.15)$, the more willingly he or she assesses the illness as long term $(r=.21)$, the more severe symptoms he or she experiences $(r=.14)$, but also the better he or she understands the illness $(r=.14)$ and the less negative feelings about the illness he or she has $(r=.07)$, although the latter correlation is very weak. These correlations comply with the predictions as to the illness perception.

Clinical aspects of illness in terms of illness duration and disability status according to EDSS scores are associated with subjective illness perceptions measured by the Brief IPQ. Illness duration, counted in years, is correlated with Timeline $(r=.17)$, Treatment control $(r=-.21)$ and Identity $(r=.13)$. The longer the illness has lasted, the more eager the patients declare their illness as chronic (as opposed to temporary). They also do not want to believe that the treatment will help them overcome the symptoms. Moreover, they perceive their illness as severe. It is worth noting that the length of the illness is unrelated to the subjective perception of its consequences, personal control over the illness, cognitive understanding, concern or emotional response.

The objective disability condition in multiple sclerosis is associated with the subjective perception of illness in 6 of 8 aspects (there are no relations in Timeline and Emotional Response only). We found that there are strong positive relations among EDSS in MS and Identity $(r=.55)$, Consequences $(r=.32)$, a moderate relationship between Kurtzke's Scale and Concern $(r=.17)$ and negative moderate correlations with Personal Control $(r=-.24)$, Treatment Control

\section{Table 5}

Test-retest reliability of the Polish Brief IPQ. Samples contain data from Hashimoto's disease (HD), ischaemic heart disease (IHD), multiple sclerosis $(M S)$, breast cancer $(B C)$, diabetes type II $(D)$, psoriasis $(P)$, rheumatoid arthritis $(R A)$, and bronchial asthma (BA) patients

\begin{tabular}{|c|c|c|c|c|c|c|c|c|c|}
\hline & $\begin{array}{c}\text { All } \\
n=358\end{array}$ & $\begin{array}{c}\text { HD } \\
n=36\end{array}$ & $\begin{array}{c}\text { IHD } \\
n=60\end{array}$ & $\begin{array}{c}M S \\
n=26\end{array}$ & $\begin{array}{c}\text { BC } \\
n=38\end{array}$ & $\begin{array}{c}\mathrm{D} \\
n=41\end{array}$ & $\begin{array}{c}\mathrm{P} \\
n=11\end{array}$ & $\begin{array}{c}\text { RA } \\
n=30\end{array}$ & $\begin{array}{c}\text { BA } \\
n=29\end{array}$ \\
\hline IP1 Consequences & $.60^{* * *}$ & $.63^{* * *}$ & $.45^{* * *}$ & $.70^{* * *}$ & $.77^{* * *}$ & $.86^{* * *}$ & $.95^{* * *}$ & $.61^{* * *}$ & $.97^{* * *}$ \\
\hline IP2 Timeline & $.68^{* * *}$ & $.87^{* * *}$ & $.67^{* * *}$ & $.72^{* * *}$ & $.57^{* * *}$ & $.73^{* * *}$ & $.97^{* * *}$ & $.92^{* * *}$ & $.57^{* *}$ \\
\hline $\begin{array}{l}\text { IP3 Personal } \\
\text { control }\end{array}$ & $.59^{* * *}$ & .24 & $.51^{* * *}$ & $.61^{* * *}$ & $.68^{* * *}$ & $.89^{* * *}$ & $.74^{*}$ & $.49^{* *}$ & $.86^{* * *}$ \\
\hline $\begin{array}{l}\text { IP4 Treatment } \\
\text { control }\end{array}$ & $.75^{* * *}$ & $.52^{* *}$ & $.65^{* * *}$ & $.70^{* * *}$ & $.87^{* * *}$ & $.84^{* * *}$ & $.92^{* * *}$ & $.53^{* *}$ & $.79^{* * *}$ \\
\hline IP5 Identity & $.65^{* * *}$ & $.76^{* * *}$ & $.55^{* * *}$ & $.92^{* * *}$ & $.76^{* * *}$ & $.91^{* * *}$ & $.75^{* *}$ & $.45^{*}$ & $.90^{* * *}$ \\
\hline IP6 Concern & $.66^{* * *}$ & $.69^{* * *}$ & $.55^{* * *}$ & $.79^{* * *}$ & $.74^{* * *}$ & $.89^{* * *}$ & $.88^{* * *}$ & $.81^{* * *}$ & $.89^{* * *}$ \\
\hline IP7 Understanding & $.60^{* * *}$ & $.53^{* *}$ & $.61^{* * *}$ & .31 & .45 & $.56^{* * *}$ & $.89^{* * *}$ & $.68^{* * *}$ & $.92^{* * *}$ \\
\hline $\begin{array}{l}\text { IP8 Emotional } \\
\text { response }\end{array}$ & $.58^{* * *}$ & $.65^{* * *}$ & $.58^{* * *}$ & $.75^{* * *}$ & $.77^{* * *}$ & $.68^{* * *}$ & $.87^{* * *}$ & $.54^{* *}$ & $.90^{* * *}$ \\
\hline
\end{tabular}

Note. ${ }^{*} p<.05 ;{ }^{* *} p<.01 ;{ }^{* * *} p<.001$ 
Table 6

Correlations between Polish Brief IPQ items and demographic, clinical and psychological variables

\begin{tabular}{lcccccccc}
\hline & IP1 & IP2 & IP3 & IP4 & IP5 & IP6 & IP7 & IP8 \\
\hline Demographic variables: & & & & & & & & \\
Gender, $n=923$ & .02 & .02 & .02 & .05 & .01 & -.01 & -.01 & .00 \\
Age, $n=923$ & $.15^{*}$ & $.21^{*}$ & .06 & -.06 & $.14^{*}$ & -.04 & $.14^{*}$ & $-.07^{*}$ \\
Educational level, $n=787$ & .01 & $-.09^{*}$ & .03 & .06 & -.03 & -.03 & .05 & -.04 \\
Clinical variables: & & & & & & & & \\
Illness duration, $n=580$ & .04 & $.17^{*}$ & -.03 & $-.21^{*}$ & $.13^{*}$ & -.08 & -.02 & -.04 \\
Age at onset, $n=514$ & -.03 & -.01 & .08 & .06 & -.05 & -.08 & .07 & $-.11^{*}$ \\
EDSS (MS), $n=140$ & $.32^{*}$ & .01 & $-.24^{*}$ & $-.29^{*}$ & $.55^{*}$ & $.17^{*}$ & $-.23^{*}$ & .03
\end{tabular}

Behavioural variables (coping with chronic illness strategies):

COPE $n=770$

\begin{tabular}{lcccccccc} 
PROBLEM & .06 & -.03 & $.13^{* * *}$ & $.16^{* * *}$ & -.01 & .02 & $.12^{* *}$ & .01 \\
EMOTIONS & $.21^{*}$ & .03 & -.07 & -.05 & $.20^{* * *}$ & $.30^{*}$ & $-.10^{* *}$ & $.43^{* * *}$ \\
ACCEPTANCE & -.02 & .04 & $.12^{*}$ & $.08^{*}$ & -.01 & $-.16^{* * *}$ & $.19^{* * *}$ & $-.10^{* *}$ \\
\hline
\end{tabular}

Note. ${ }^{*} p<.05,{ }^{* *} p<.01,{ }^{* * *} p<.001$

EDSS - Expanded Disability Status Scale (for MS patients); COPE - Coping Orientations to Problems Experienced; PROBLEM Problem Focused Coping; EMOTIONS - Focus on and Venting of Emotions

$(r=-.29)$ and Understanding $(r=-.23)$. These results are proof of concurrent validity for the Brief IPQ.

The age at onset is not related to the Brief IPQ items despite the Emotional Response $(r=-.11)$. This means that the later the patients became ill, the less negative emotions they experience in connection with their illness. This is quite a weak correlation.

A deeper verification of concurrent validation was possible thanks to the ratios of correlation between the strategies of coping with the stress connected with a chronic illness and particular aspects of the illness perception. We expected that coping strategies, such as Problem Focused Coping, Focus on and Venting of Emotions and Acceptance, would correlate with the illness perception because, according to Leventhal's concept (Leventhal et al., 2003) behaviour is determined by the illness perceptions. Since the illness perceptions are mental representations of a cognitive and emotional nature, the choice of cognitive strategies (Problem Focused Coping) and emotional strategies (Focus on and Venting of Emotions) would be most appropriate for this empirical construct. We predicted that the emotional strategy would correlate with the Emotional Response item and the Concern item and, on the other hand, that the task strategy would correlate with Personal Control, Treatment Control and Understanding items. However, the illness acceptance as the task strategy indicating the patient's adaptation to illness should correlate with the illness perceptions, especially with regard to comprehension (the Understanding item), the declared sense of control over the illness (Person- al Control) and other aspects deemed beneficial for coping with the stress of a chronic illness.

Pearson coefficients were calculated to find significant relations between coping strategies and illness perceptions. The analysis revealed that illness perceptions components are moderately associated with mentioned chronic illness coping strategies. It proved that the task strategy is positively correlated with Personal Control $(r=.13)$, Treatment Control $(r=.16)$ and Understanding $(r=.12)$. The remaining aspects of illness perceptions are not related to the task strategy.

Focus on and Venting of Emotions is correlated with Emotional Response $(r=.43)$ and Concern $(r=.30)$, as we predicted. We did not expect that there would also be positive relationships between Focus on and Venting of Emotions strategy and Consequences or Identity, but we revealed these relationships. We also revealed that this emotional strategy is negatively correlated with Understanding (Table 6).

The correlation between Acceptance and illness perceptions leads us to conclude that this strategy correlates positively with Understanding, Personal Control and Treatment Control, as we suspected. The research results also show that the illness acceptance strategy correlates negatively with Emotional Response and Concern. These relationships prove that the acceptance strategy has positive consequences for illness perception. A patient who applies the illness acceptance strategy has a better sense of control over the illness, believes more in the treatment and better understands the illness itself. Additionally, such a pa- 
tient worries less about the illness and experiences less unpleasant emotions (Table 6). All the aspects of the illness evoke beneficial illness perceptions.

\section{DISCRIMINANT VALIDITY}

To diversify the illness perception among patients suffering from different illnesses, one-way ANOVA with Tukey HSD post hoc tests was carried out. In order to do that, the largest groups of patients (90 and more) participating in the study were selected to be thoroughly compared. Thus, the IHD, P, BC and MS patients participated in the study (see Table 7). Despite suffering from a chronic illness, these patients differed in terms of health condition, severity and quality of illness, sense of control connected with the treatment possibilities or the knowledge of the causes, which is associated with the sense of predictability of the course of illness and the influence on emotional functioning. It was assumed that in terms of the subjective illness perceptions these patient would differ.

In the test, the independent variable was the illness and the dependent variable was each aspect of illness perceptions. Eight one-way ANOVA analyses were conducted. We found that each item distinguished the patients' group. It means that people assess their illness perceptions in accordance with their suffering. The results show that diversity in the perception of illness depending on the type of illness occurs, although to a moderate extent. There are aspects of illness perception which are similar and different depending on the type of illness. To sum up, we can state that depending on the type of illness, a patient perceives the illness and its aspects differently, and this illness perception is measured by the Brief IPQ. The differences are significant although not identical in all cases, which proves the discriminant validity of the questionnaire.

\section{DISCUSSION}

The aim of this study was to present the psychometric values for the Polish version of the Brief Illness Perception Questionnaire constructed by Broadbent et al. (2006), which is a shorter version of the Illness Perception Questionnaire-Revised (Moss-Morris et al., 2002). The tool is widely used by health science researchers from many countries. It is very useful because it is short and very easy for patients to fill in. Polish researchers are also very interested in using the Brief IPQ.

The results of the psychometric analysis of the B-IPQ show that the questionnaire can be useful for the Polish population of ill people. Although the questionnaire has been translated into 36 languag-

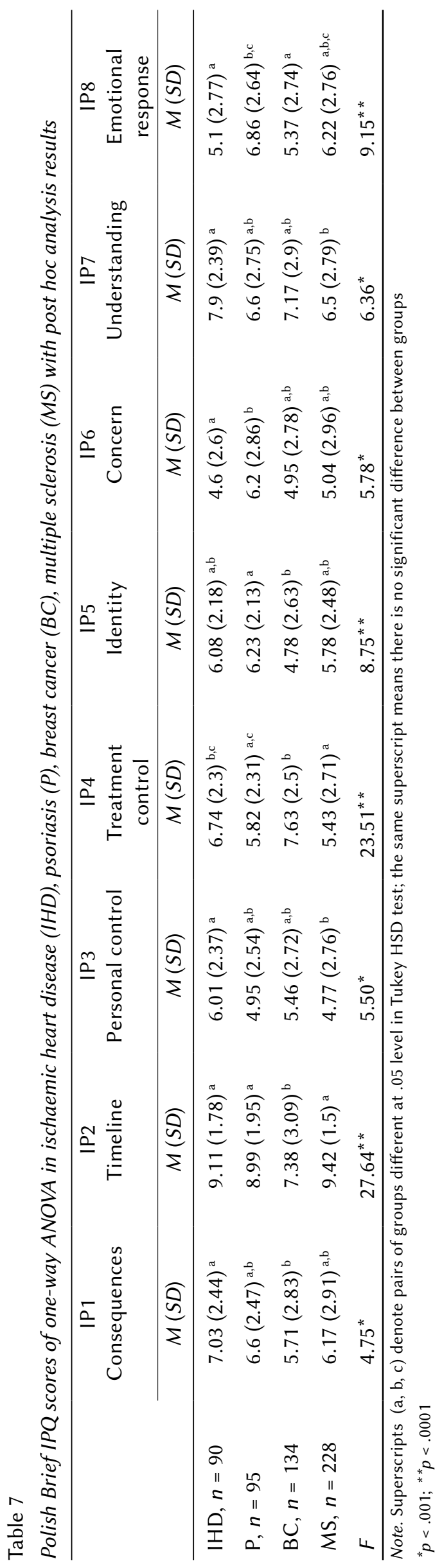

Polish Brief IPQ 
es, there are only a few published adaptation studies (Broadbent et al., 2015). We managed to find a cohesive study in Spanish (Pacheco-Huergo et al., 2012), Danish (Raaij, Schröder, Maissan, Pool, \& Wittink, 2012), Dutch (Hallegraeff, Schans, van der Krijnen, \& Greef, 2013) and Farsi (Bazzazian \& Besharat, 2010).

To begin with, we want to elaborate on particular items in the Polish language version of the questionnaire, starting with the most empirically controversial. We need to remember that the construction of the questionnaire requires that each item be analysed separately, and therefore we feel obliged to discuss the psychometric values of each particular item.

First of all, item 7 (Understanding), which measures comprehensibility in the Polish version, seems to be the least stable. Generally speaking, this item is stable for most diseases; however, in two cases of our research we did not observe any correlation of results at times $\mathrm{t} 1$ and $\mathrm{t} 2$. Perhaps the reason for that was the insufficient number of participants ( $n=26$ for MS patients) or the situational factors (e.g. the place), which were not very carefully controlled in this research. On the other hand, the content of the comprehensibility item is very general, quite vague and may be seen by respondents as ambiguous. The question about whether the patient understands his/her illness or not is a question about many unspecified factors which constitute the cognitive perception of illness, but it is formulated in only one item. Therefore, probably the patient refers to some feeling of understanding the illness instead of specific cognitive aspects of such understanding. Consequently, different responses, even inconsistent, are possible. The understanding item itself does not correlate with the functional impact of illness; in particular it is not related in any way to the perception of consequences or the perception of the severity of illness, which makes the researcher wonder even more what indeed this item measures. The results of other research (e.g. tests on patients with pacemakers implanted; Rakhshan, Hassani, Ashktorab, \& Majd, 2013) show that the understanding of illness may be that component of the illness perception which is most susceptible to change, especially in an educational process. The result for MS and cancer patients in this research also proves that the understanding of illness may change in time. However, from the studies on the revised version of the questionnaire (IPQ-R) we conclude that in terms of illness coherence this stability refers to BC patients (Rees, Fry, Cull, \& Sutton, 2004). The inconsistency suggests that one item cannot measure such a complex phenomenon as the subjective understanding of illness and that further study on the short version of the IPQ is necessary, especially with regard to the aspect of understanding the illness. Similar methodological problems were reported by van Oort, Schröder, and French (2011) in a study on the questionnaire applying the "think-aloud" method. However, Broadbent,
Kaptein, and Petrie (2011) successfully challenged them by highlighting the unreliability of the research and poor reliability of the method applied. Their conclusion shows the necessity to properly translate and adapt the questionnaire. Therefore, we insist that the Understanding item is interpreted rather carefully when analysing the results.

The examination of external validity of the IPQ provides additional information on item IP7. The correlations of this item with coping strategies prove that the Understanding item is related to the Problem Focused Coping $(r=.12)$ and Acceptance $(r=.19)$ but negatively related to the Focus on and Venting of Emotions $(r=-.10)$. This result allows us to conclude that this item is adaptive, and its correlations with beneficial and effective coping strategies confirm that the subjective understanding of chronic illness is a positive aspect of the illness perceptions.

Another discussed item is IP2 (Timeline). The patient was asked how long in his/her opinion the illness would last. Since the respondents were mainly chronically ill patients, we would expect an answer stating that the illness would last till the end of life (i.e. 10 on the Likert scale). This expectation was actually confirmed except for acne patients. This strong faith that the illness would be relatively short (the mean was 4.42) was expressed by acne patients who were relatively young (their mean age was 18.98 years) and was connected with the belief that common acne is associated only with puberty. This short declared duration of illness proves at the same time the accuracy of the Timeline item as only in the case of acne, perceived as a usually temporary illness, was the duration of illness so short (the too small number of acne patients prevented us from carrying out a comparative analysis with other illnesses; nevertheless, we addressed our observation as a tendency which should be confirmed in further studies using bigger samples). In all other instances patients agreed that their illness was chronic. Researchers are still not sure if it is beneficial to be aware that illness will last forever or short because it depends on the objective nature of the illness - whether it is acute or chronic. When the illness is chronic, it is favourable for a patient to assess that the illness would last forever because the awareness of the patient's real situation can make his/her behaviour well fitted to the outcome of coping processes. Sometimes it is better for a chronically ill person to believe that his/her illness would last briefly, as the fighting spirit is the most important aspect of coping with chronic illness, being a type of a denial strategy (e.g. Greer, Moorey, \& Watson, 1989; Watson, Haviland, Greer, Davidson, $\&$ Bliss, 1999). As we can see, the relations between the subjective perception of illness duration and positive coping require further empirical verification. So far in our study we have not found any relations between Timeline and coping strategies. 
The natural state of the Timeline item was also confirmed by correlations with demographic and clinical aspects, i.e. with illness duration and age. These results are the evident manifestation of accuracy of a particular item. The older the chronically ill patient is and the longer the illness has lasted, the more willingly the patient declares that he/she suffers from a chronic illness.

The Personal Control item (IP3) strongly correlates with other questionnaire items and remains stable in time with respect to many groups of patients except for the persons suffering from heart diseases. Obviously, the feeling of control in the group of patients is an aspect variable in time; thus, we should investigate the dynamics and the factors determining the subjective control over illness measured with only one item. Another correlation shows that IP3 does not correlate with demographic variables or illness duration, but correlates negatively with the objective illness severity measured in MS patients using the EDSS $(r=.24)$. The greater the patient's motor disability, the weaker the subjective control over the illness. The correlation of this item with coping strategies shows that the feeling of control refers to those patients who cope with the illness by applying task-oriented strategies $(r=.13)$ and accept the illness more $(r=.12)$. Similar relations can be found in people who have strong belief in treatment (IP4). However, in this case those who believe more are the patients whose illness is relatively short $(r=-.21)$ and who are more able in terms of the EDSS (it refers to MS patients only; $r=-.29$ ). We noted that in general both the items Personal Control and Treatment Control show similar relations with demographic, clinical and behavioural variables. The only thing that distinguishes these two items is the negative relation between Treatment Control and illness duration with the absence of a relation between Personal Control and illness duration. The belief in treatment is stronger in those patients whose illness duration is short, whereas the sense of control does not depend on the duration of illness.

The subjective perception of illness severity, i.e. the Identity item (IP5), is correlated with age $(r=.14)$, but also sometimes with the duration of illness $(r=.13)$; it correlates relatively highly positively with the objective assessment of disability in MS $(r=.55)$, which indicates quite high reliability of the subjective measure in comparison with the objective measure of symptoms perception. Seriously ill patients are more eager to cope with their illness using the strategy of concentrating on and expressing emotions $(r=.20)$. The task-oriented strategies fail when the burden of symptoms gets heavy; then the patient has to cope with his/her difficult emotions through expression of and control over them. Previous research has already shown this type of dependency in coping with situations where control is hindered or impossible (see:
Zeidner \& Saklofske, 1996; Aldwin, 1994; Vitaliano, DeWolfe, Maiuro, Russo, \& Katon, 1990).

Emotional response (IP8) and Concern (IP6) are very similar items in terms of correlations between them and coping strategies. They both correlate with Focus on and Venting of Emotions (positively), Acceptance (negatively) and do not correlate with Problem Focused Coping (see Table 6). Both aspects of illness perception (high emotional response and high concern) seem to be very detrimental to the patient, as he/she is prone to react to the illness with quite unfavourable coping strategies. Furthermore, Emotional response and emotional strategy of coping with chronic illness comprise mutual variance. The correlations between them are relatively high.

However, these two items are not totally identical. It was noted that there is no relation between Concern and the patient's age but there is a correlation between Emotional Response and age, although at a low negative level. Similar observations were made with regard to the age at onset. Those patients who became ill when relatively young state that the illness has significantly affected their emotional condition; we do not observe this relation in patients who worry themselves about their illness. Another interesting fact is that the MS patients who are objectively less able worry about the illness much more; however, no relation between EDSS and the Emotional Response item was found. This result is inconsistent with the claim that disabled MS patients state that the illness negatively influences their emotional condition. The result should be examined in future research and verified in terms of other variables.

It is worth highlighting once more the relation between the objective patient's condition measured with the EDSS (including MS patients) and the subjective illness perception. In general, this relation is present in almost every aspect measured by the short version of the IPQ except the timeline and emotional response, as it was mentioned above. This result may be characteristic of MS patients and should not be generalized to all research. However, the results draw our attention to the function of the subjective illness perception, which does not necessarily coincide with clinical features of illness in selected aspects. Therefore, this objective aspect should be included in research carried out, as when compared to the subjective aspect, it provides a wider picture of the relations between the actual condition and the condition perceived by patients. The results of this research prove the existence of concurrent validity of the Brief IPQ in the Polish version.

To conclude, firstly, the results of this study are very helpful in assessing the validity of the Polish version of the Brief IPQ. We are sure the findings of this study strongly indicate the reliability and validity of the Polish adaptation of the Brief IPQ. Polish researchers can successfully use this tool in their 
studies, and we are strongly convinced that the Polish version of the Brief IPQ is valuable and can be used in the Polish language population of chronically ill people. It is also a good idea to compare the results obtained in the Polish version to the results of English speakers in future.

Secondly, Brief IPQ is a very short questionnaire. The suffering patients, who do the scientists a favour by participating in psychological research, deserve not to be subject to long-lasting and complex

Marlena M. Kossakowska, Tomasz J. Stefaniak research procedure. They usually show good will to help researchers do their work but often give up because they are unable to complete laborious tests due to tiredness or lack of time. This is why short research tools are a good solution for them (see the study on palliative care: Price et al., 2012).

The results of this research also reveal some limitations of the Brief IPQ. Its strength may turn out to be its weakness, so the short version of the questionnaire may not provide the full picture of the cognitive and emotional representation of illness. The short version is limited to a few necessary elements that need to be talked about quite decidedly. This is shown for instance by the values of skewness and kurtosis (Table 3), which are sometimes different and rather high in some instances. This conclusion refers mainly to the Timeline item, but as it has been already mentioned, the participants in the research were selected from among patients suffering from an objectively long-term illness.

Furthermore, no research has been carried out in Poland on the predictive validity of the Brief IPQ in particular illnesses. We did not correlate the Brief IPQ with the IPQ-R in the Polish version (Wojtyna, Soroka, \& Chełkowska, 2014). We also need further research on bigger samples using other new tool measures, e.g. Me and My Disease Scale (Kwissa-Gajewska, Kroemeke, \& Heszen, 2015) or Illness Self-Assessment Scale (Janowski, Steuden, Kuryłowicz, \& Nieśpiałowska-Steuden, 2007) or My Skin Questionnaire (Kossakowska \& Cieścińska, 2016).

The other limitation is the fact that our research did not include other objective factors connected with illness perception; in the group of multiple sclerosis patients we limited the research scope only to include the motor disability scale assessed by neurologists. We could make use of other more reliable physiological or biochemical indices, as in the research carried out by Broadbent et al. (2006) or Bazzazian and Besharat (2010).

We would like to encourage Polish researchers to use the Brief IPQ because it is a useful, reliable and accurate research tool which, being easy to use, does not cause any problems to a patient. Although there has been some research carried out using the questionnaire, their function remains only exploratory (Kossakowska \& Zielazny, 2013; Kossakowska \& Zemła-Sieradzka, 2011), whereas further study would enable us to better understand the patient in the face of an illness.

Funding source: Polish National Science Centre Grant DEC-2011/03/B/HS6/01117 for Dr. Marlena Kossakowska.

\section{References}

Aldwin, C. (1994). Stress, coping, and development: An integrative perspective. New York: Guilford Press.

Bazzazian, S., \& Besharat, M. A. (2010). Reliability and validity of a Farsi version of the brief illness perception questionnaire. Procedia - Social and Behavioral Sciences, 5, 962-965.

Broadbent, E., Donkin, L., \& Stroh, J. C. (2011). Illness and treatment perceptions are associated with adherence to medications, diet, and exercise in diabetic patients. Diabetes Care, 34, 338-340.

Broadbent, E., Kaptein, A. A., \& Petrie, K. J. (2011). Commentary: Double Dutch: The 'think-aloud' Brief IPQ study uses a Dutch translation with confusing wording and the wrong instructions. British Journal of Health Psychology, 16, 246-249.

Broadbent, E., Petrie, K. J., Main, J., \& Weinman, J. (2006). The Brief Illness Perception Questionnaire. Journal of Psychosomatic Research, 60, 631-637.

Broadbent, E., Wilkes, C., Koschwanez, H., Weinman, J., Norton, S., \& Petrie, K. J. (2015). A systematic review and meta-analysis of the Brief Illness Perception Questionnaire. Psychology \& Health, 30, 1361-1385.

Bucks, R. S., Hawkins, K., Skinner, T. C., Horn, S., Seddon, P., \& Horne, R. (2009). Adherence to treatment in adolescents with cystic fibrosis: The role of illness perceptions and treatment beliefs. Journal of Pediatric Psychology, 34, 893-902.

Byer, B., \& Myers, L. B. (2000). Psychological correlates of adherence to medication in asthma. Psychology, Health \& Medicine, 5, 389-393.

Cartwright, T., Endean, N., \& Porter, A. (2009). Illness perceptions, coping and quality of life in patients with alopecia. British Journal of Dermatology, 160, 1034-1039.

Carver, C. S., Scheier, M. F., \& Weintraub, J. K. (1989). Assessing coping strategies: a theoretical based approach. Journal of Personality and Social Psychology, 56, 267-283.

Chen, S. L., Tsai, J. C., \& Chou, K. R. (2011). Illness perceptions and adherence to therapeutic regimens among patients with hypertension: A structural modeling approach. International Journal of Nursing Studies, 48, 235-245.

Cheng, C., Chan, A. O. O., Hui, W. M., \& Lam, S. K. (2003). Coping strategies, illness perception, anxiety and depression of patients with idiopathic constipation: A population-based study. Alimentary Pharmacology and Therapeutics, 18, 319-326. 
Chilcot, J., Wellsted, D., \& Farrington, K. (2010). Illness representations are associated with fluid nonadherence among hemodialysis patients. Journal of Psychosomatic Research, 68, 203-212.

Edwards, R., Suresh, R., Lynch, S., Clarkson, P., \& Stanley, P. (2001). Illness perceptions and mood in chronic fatigue syndrome. Journal of Psychosomatic Research, 50, 65-68.

Evans, D., \& Norman, P. (2009). Illness representations, coping and psychological adjustment to Parkinson's disease. Psychology \& Health, 24, 1181-1196.

Fortune, D. G., Richards, H. L., Main, C. J., \& Griffiths, C. E. M. (2000). Pathological worrying, illness perceptions and disease severity in patients with psoriasis. British Journal of Health Psychology, 5, 71-82.

Gauchet, A., Tarquinio, C., \& Fischer, G. (2007). Psychosocial predictors of medication adherence among persons living with HIV. International Journal of Behavioural Medicine, 14, 141-150.

Greer, S., Moorey, S., \& Watson, M. (1989). Patients' adjustment to cancer: The mental adjustment to cancer (MAC) scale vs. clinical ratings. Journal of Psychosomatic Research, 33, 373-377.

Griva, K., Myers, L. B., \& Newman, S. (2000). Illness perceptions and self-efficacy beliefs in adolescents and young adults with insulin dependent diabetes mellitus. Psychology \& Health, 15, 733-750.

Hagger, M. S., \& Orbell, S. (2003). A meta-analytic review of the common-sense model of illness representations. Psychology \& Health, 18, 141-184.

Hallegraeff, J. M., Schans, C. P., van der, Krijnen, W. P., \& Greef, M. H. G. de (2013). Measurement of acute nonspecific low back pain perception in primary care physical therapy: reliability and validity of the brief illness perception questionnaire. BMC Musculoskeletal Disorders, 14, 53. doi: 10.1186/1471-2474-14-53

Heijmans, M. (1998). Coping and adaptive outcome in chronic fatigue syndrome: importance of illness cognitions. Journal of Psychosomatic Research, 45, 39-51.

Heijmans, M. (1999). The role of patients' illness representations in coping and functioning with Addison's disease. British Journal of Health Psychology, 4, 137-149.

Heijmans, M., \& de Ridder, D. (1998). Assessing illness representations of chronic illness: Explorations of their disease-specific nature. Journal of Behavioral Medicine, 21, 485-503.

Helder, D. I., Kaptein, A. A., Van Kempen, G. M. J., Weinman, J., Van Houwelingen, J. C., \& Roos, R. A. C. (2002). Living with Huntington's disease: illness perceptions, coping mechanisms, and spouses' quality of life. International Journal of Behavioral Medicine, 9, 37-52.

Heszen-Klemens, I. (1979). Poznawcze uwarunkowania zachowania się wobec własnej choroby [Cog- nitive determinants of illness behaviour]. Warszawa: PAN.

Horne, R., Chapman, S. C. E., Parham, R., Freemantle, N., Forbes, A., \& Cooper, V. (2013). Understanding patients' adherence-related beliefs about medicines prescribed for long-term conditions: a meta-analytic review of the necessity-concerns framework. PLoS One, 8, e80633. doi: 10.1371/journal.pone.0080633

Horne, R., \& Weinman, J. (1999). Patients' beliefs about prescribed medicines and their role in adherence to treatment in chronic physical illness. Journal of Psychosomatic Research, 47, 555-567.

Janowski, K., Steuden, S., Kuryłowicz, J., \& Nieśpiałowska-Steuden, M. (2007). Skala Oceny Własnej Choroby: narzędzie pomiaru percepcji sytuacji choroby. Psychologiczni Perspektywy, 10, 104-118.

Kaptein, A. A., Scharloo, M., Fischer, M. J., Snoei, L., Cameron, L. D., Sont, J. K., Rabe, K. F., \& Weinman, J. (2008). Illness perceptions and COPD: an emerging field for COPD patient management. The Journal of Asthma, 45, 625-629.

Kim, Y., \& Evangelista, L. S. (2010). Relationship between illness perceptions, treatment adherence, and clinical outcomes in patients on maintenance hemodialysis. Nephrology nursing journal: Journal of the American Nephrology Nurses' Association, 37, 271-280.

Kodeks Etyczno-Zawodowy Psychologa [The Psychologist's Code of Professional Ethics]. (1996). Warsaw: Polskie Towarzystwo Psychologiczne.

Kossakowska, M., \& Cieścińska, C. (2016). My Skin, a self-questionnaire for assessment of the emotional-cognitive representation of skin. Health Psychology Report, 4. doi: 10.5114/hpr.2016.57692

Kossakowska, M., \& Zemła-Sieradzka, L. (2011). Wybrane aspekty wzrostu osobistego u osób chorych na stwardnienie rozsiane (SM) [Some positive aspects of coping with chronic illness in patients with multiple sclerosis]. Postępy Psychiatrii i Neurologii, 20, 259-267.

Kossakowska, M., \& Zielazny, P. (2013). Obraz choroby, radzenie sobie ze stresem oraz korzyści psychospołeczne u osób zakażonych wirusem HIV i chorych na AIDS [IIlness perceptions, coping, and benefit finding among HIV/AIDS patients]. Postępy Psychiatrii i Psychologii, 22, 177-186.

Kulczycki, M. (1971). Psychologiczne problemy człowieka chorego [Psychological issues of chronically ill people]. Wrocław: Zakład Narodowy im. Ossolińskich.

Kurtzke, J. F. (1983). Rating neurologic impairment in multiple sclerosis: an expanded disability status scale (EDSS). Neurology, 33, 1444-1452.

Kwissa-Gajewska, Z., Kroemeke, A., \& Heszen, I. (2015). The Me and My Disease Scale: measuring state hope and determining its impact on coping in patients with type 2 diabetes mellitus and my- 
ocardial infarction. Health Psychology Report, 3, 167-177.

Leventhal, H., Brissette I., \& Leventhal, E. A. (2003). The common-sense model of self-regulation of health and illness. In L. D. Cameron \& H. Leventhal (eds.), The Self-Regulation of Health and Illness Behaviour (pp. 42-65). London: Routledge.

Leventhal, H., Nerenz, D. R., \& Steele, D. J. (1984). Illness representations and coping with health threats. In A. Baum, S. E. Taylor, \& J. E. Singer
Marlena M. Kossakowska, Tomasz J. Stefaniak (eds.), Handbook of Psychology and Health, Vol. IV: Social Psychological Aspects of Health (pp. 219252). Hillsdale: NJ7 Erlbaum.

Llewellyn, C. D., Miners, A. H., Lee, C. A., Harrington, C., \& Weinman, J. (2003). The illness perceptions and treatment beliefs of individuals with severe haemophilia and their role in adherence to home treatment. Psychology \& Health, 18, 185-200.

Massey, E. K., Tielen, M., Laging, M., Beck, D. K., Khemai, R., Gelder, T. van, \& Weimar, W. (2013). The role of goal cognitions, illness perceptions and treatment beliefs in self-reported adherence after kidney transplantation: A cohort study. Journal of Psychosomatic Research, 75, 229-234.

Mc Sharry, J., Moss-Morris, R., \& Kendrick, T. (2011). Illness perceptions and glycaemic control in diabetes: a systematic review with meta-analysis. Diabetic Medicine, 28, 1300-1310.

Moss-Morris, R. (1997). The role of illness cognitions and coping in the aetiology and maintenance of chronic fatigue syndrome (CFS). In K. J. Petrie \& J. A. Weinman (eds.), Perceptions of Health and Illness: Current Research and Applications (pp. 411439). Amsterdam: Harwood Academic Publishers.

Moss-Morris, R., \& Chalder, T. (2003). Illness perceptions and levels of disability in patients with chronic fatigue syndrome and rheumatoid arthritis. Journal of Psychosomatic Research, 55, 305-308.

Moss-Morris, R., Weinman, J., Petrie, K. J., Horne, R., Cameron, L. D., \& Buick, D. (2002). The Revised Illness Perception Questionnaire (IPQ-R). Psychology \& Health, 17, 1-16.

Murphy, H., Dickens, C., Creed, F., \& Bernstein, R. (1999). Depression, illness perception and coping in rheumatoid arthritis. Journal of Psychosomatic Research, 46, 155-164.

Nicklas, L. B., Dunbar, M., \& Wild, M. (2010). Adherence to pharmacological treatment of non-malignant chronic pain: the role of illness perceptions and medication beliefs. Psychology \& Health, 25, 601-615.

Oort, L. van, Schröder, C., \& French, D. P. (2011). What do people think about when they answer the Brief Illness Perception Questionnaire? A "think-aloud" study. British Journal of Health Psychology, 16, 231-245.

Pacheco-Huergo, V., Viladrich, C., Pujol-Ribera, E., Cabezas-Peña, C., Núñez, M., Roura-Olmeda, P.,
Amado-Guirado, E., Núñez, E., \& Del Val, J. L. (2012). Perception in chronic illnesses: linguistic validation of the revised Illness Perception Questionnaire and the Brief Illness Perception Questionnaire for a Spanish population. Atencion Primaria / Sociedad Española de Medicina de Familia y Comunitaria, 44, 280-287. doi: 10.1016/j. aprim.2010.11.022

Petrie, K. J., \& Weinman, J. (1996). Role of patients' view of their illness in predicting return to work and functioning after myocardial infarction. British Medical Journal (International Edition), 312, 1191-1194.

Petrie, K. J., \& Weinman, J. (2006). Why illness perceptions matter. Clinical Medicine, 6, 536-539.

Platt, I., Green, H., Jayasinghe, R., \& Morrissey, S. (2014). Understanding adherence in patients with Coronary Heart Disease: Illness representations and readiness to engage in healthy behaviours. Australian Psychologist, 49, 127-137.

Price, A., Goodwin, L., Rayner, L., Shaw, E., Hansford, P., Sykes, N., Monroe, B., Higginson, I., Hotopf, M., \& Lee, W. (2012). Illness perceptions, adjustment to illness, and depression in a palliative care population. Journal of Pain and Symptom Management, 43, 819-932.

Raaij, E. J. de, Schröder, C., Maissan, F. J., Pool, J. J., \& Wittink, H. (2012). Cross-cultural adaptation and measurement properties of the Brief Illness Perception Questionnaire-Dutch Language Version. Manual Therapy, 17, 330-335.

Rakhshan, M., Hassani, P., Ashktorab, T., \& Majd, H. A. (2013). The nature and course of illness perception following cardiac pacemaker implantation: A self-regulatory approach. International Journal of Nursing Practice, 19, 318-325.

Rees, G., Fry, A., Cull, A., \& Sutton, S. (2004). Illness perceptions and distress in women at increased risk of breast cancer. Psychology \& Health, 19, 749-765.

Rees, G., Leong, O., Crowston, J. G., \& Lamoureux, E. L. (2010). Intentional and unintentional nonadherence to ocular hypotensive treatment in patients with glaucoma. Ophthalmology, 117, 903-908.

Rozema, H., Völlink, T., \& Lechner, L. (2009). The role of illness representations in coping and health of patients treated for breast cancer. Psychooncology, 18, 849-857.

Scharloo, M., Kaptein, A. A., Weinman, J., Hazes, J. M., Willems, L. N. A., Bergman, W., \& Rooijmans, H. G. M. (1998). Illness perceptions, coping and functioning in patients with rheumatoid arthritis, chronic obstructive pulmonary disease and psoriasis. Journal of Psychosomatic Research, 44, 573-585.

Scharloo, M., Kaptein, A. A., Weinman, J., Bergman, W., Vermeer, B. J., \& Rooijmans, H. G. M. (2000). Patients' illness perceptions and coping 
as predictors of functional status in psoriasis: A 1-year follow-up. British Journal of Dermatology, 142, 899-907.

Searle, A., \& Murphy, S. (2000). Representations of illness: Their relationship with an understanding of and adherence to homoeopathic treatment. Psychology, Health \& Medicine, 5, 179-191.

Tiggelman, D., Ven, M. O. M. van de, Schayck, O. C. P. van, Kleinjan, M., \& Engels, R. C. M. E. (2014). The Common Sense Model in early adolescents with asthma: Longitudinal relations between illness perceptions, asthma control and emotional problems mediated by coping. Journal of Psychosomatic Research, 77, 309-315.

Vitaliano, P. P., DeWolfe, D. J., Maiuro, R. D., Russo, J., \& Katon, W. (1990). Appraised changeability of a stressor as a modifier of the relationship between coping and depression: A test of the hypothesis of fit. Journal of Personality and Social Psychology, 59, 582-592.

Watson, M., Haviland, J. S., Greer, S., Davidson, J., \& Bliss, J. M. (1999). Influence of psychological response on survival in breast cancer: A population-based cohort study. Lancet, 354, 1331-1336.

Weinman, J., Petrie, K. J., Moss-Morris, R., \& Horne, R. (1996). The Illness Perception Questionnaire: a new method for assessing the cognitive representation of illness. Psychology \& Health, 11, 431-445.

Whitmarsh, A., Koutantji, M., \& Sidell, K. (2003). Illness perceptions, mood and coping in predicting attendance at cardiac rehabilitation. British Journal of Health Psychology, 8, 209-221.

Wojtyna, E., Sosoka, K., \& Chełkowksa, M. (2014). Percepcja choroby u pacjentów i ich partnerów a podejmowanie zachowań prozdrowotnych przez osoby z chorobą wieńcową serca [Patients' and their spouses' illness perception and health behaviors among patients with coronary heart disease]. Problemy Medycyny Rodzinnej, 1-2, 13-21.

Wrześniewski, K. (1996). Pomiar radzenia sobie ze stresem - wybrane zagadnienia [Coping strategies measurement - selected aspects]. Promocja Zdrowia, Nauki Spoteczne i Medycyna, 3, 34-46.

Zeidner, M., \& Saklofske, D. (1996). Adaptive and maladaptive coping. In M. Zeidner \& N. S. Endler (eds.), Handbook of coping: Theory research applications (pp. 505-531). New York: Wiley. 